\title{
Knowledge and attitudes of Iranian dental students regarding infection control during the COVID-19 pandemic
}

\author{
Mohammad ESMAEELINEJAD(a) \\ Majid MIRMOHAMMADKHANI(b) \\ Amin NAGHIPOUR(c) \\ Sogand HASANIAN(c) \\ Sara KHORASANIAN(c) iD \\ (a) Semnan University of Medical Sciences, \\ School of Dentistry, Department of Oral and \\ Maxillofacial Surgery, Semnan, Iran. \\ (b)Semnan University of Medical Sciences, \\ Social Determinants of Health Research \\ Center, Semnan, Iran. \\ (c) Semnan University of Medical Sciences \\ Dental Student Research Committee, \\ Semnan, Iran.
}

Declaration of Interests: The authors certify that they have no commercial or associative interest that represents a conflict of interest in connection with the manuscript.

Corresponding Author:

Mohammad Esmaeelinejad

E-mail: esmaeelnejad@gmail.com

https://doi.org/10.1590/1807-3107bor-2020.vol34.0121

Submitted: June 12, 2020

Accepted for publication: July 1, 2020

Last revision: September 18, 2020
Abstract: COVID-19 is an emerging and rapidly-evolving situation. This study aimed to measure the level of knowledge and attitude of the Iranian dental students towards COVID-19 and its infection control strategies. This cross-sectional study was designed using a web-based method. The questionnaire associated with COVID-19 was sent to all Iranian students in the clinical course. The extracted data regarding the knowledge and attitude of the students were statistically analyzed. In this study, 531 dental students of the clinical course in 32 Iranian universities were included. The mean age of the participants was $23.13 \pm 2.29$ years. The average percentage of knowledge and attitude scores were 59.7\% (moderate) and 66.0\% (neutral), respectively. The association between the attitude of the students and their semesters was statistically significant $(\mathrm{r}=0.183, \mathrm{p}<0.001)$. The age of the students was also significantly associated with their attitudes $(r=0.150, p=0.001)$. The outbreak of COVID-19 might resurge due to re-opening of the dental faculties. Training courses on COVID-19 infection prevention strategies should be held for dental students, especially the junior ones, and the guidelines should be sent to all of them.

Keywords: Coronavirus; COVID-19; Dentistry; Infection Control; Knowledge.

\section{Introduction}

COVID-19 is an infectious disease caused by Severe Acute Respiratory Syndrome Coronavirus 2 (SARS-CoV-2). ${ }^{1}$ The World Health Organization (WHO) on March 11, 2020, has declared the novel coronavirus (COVID-19) outbreak a global pandemic. ${ }^{2}$ COVID-19 is a serious threat to global public health. The COVID-19 outbreak led to a public health emergency in every country. ${ }^{3}$ With the fatality of this infectious disease being reported to be up to $15 \%,{ }^{5}$ over fourteen million confirmed cases of COVID-19 have been reported all around the world. ${ }^{4}$ Controlling the morbidity and mortality rates of COVID-19 is the major concern of the healthcare systems of all countries.

The transmissibility of COVID-19 is higher than that of other similar respiratory diseases such as severe acute respiratory syndrome (SARS-CoV) and the Middle East respiratory syndrome coronaviruses (MERS-CoV) and $\mathrm{R}_{0}$ of this disease is about $3.28 .{ }^{6}$ Some protocols have been adopted in 
Iran to control the spread of COVID-19, as although a definite route of transmission of SARS-CoV-2 has not been reported, droplets and aerosols seem to be two major mechanisms of its spread. ${ }^{1}$ These protocols include closing public places, especially dental offices and dental faculties.

The battle against COVID-19 is ongoing in Iran; however, there is still the worry of experiencing resurgence in transmission by announcing the white status. With hospitals and clinics maybe facilitating the transmission of the virus to uninfected patients, ${ }^{7}$ presently Iran has become the first country to report the second wave of coronavirus infection. According to an article published by the New York Times in March 2020, dentists are more susceptible to be infected by SARS-CoV-2 than medical doctors and nurses. ${ }^{8}$ The release of aerosol during dental procedures puts the dentists at a higher risk of getting infected. Hence elective dental procedures and oral surgeries have been suspended in several countries. ${ }^{9}$

Since it has been decided to open the dental faculties in Iran, this study aimed to evaluate the knowledge and attitude of Iranian dental students towards the control of the COVID-19 infection in dental schools, with the knowledge and attitude of dental students being very important to help prevent COVID-19 transmission among themselves, to uninfected patients, and to hospital staff.

\section{Methodology}

This cross-sectional study was carried out in May 2020, using an online-based method. The students were able to answer the questions online via the questionnaire website. The contact information of the students was acquired by contacting the representatives of each university. The permissions of the students were obtained before sending the questionnaires. A questionnaire on the COVID-19 pandemic and its impacts on the field of dentistry was prepared by an oral and maxillofacial surgeon according to the protocols and guidelines of infection control regarding the novel coronavirus. The questionnaire was reviewed by five dental specialist experts in infection control and informed of infectious diseases in the dentistry field and dental clinics (two oral and maxillofacial surgeons, two endodontists, and one oral and maxillofacial pathologist) to assess the content and face validity. They checked the questions to ensure they were associated with the topic and effectively captured the variables and added more related questions if necessary. The double check was executed to omit confusing questions. In a pilot study, the questionnaire was given to a random sample of 10 respondents (from the final sample) to assess reliability. The internal consistency of questions was checked by Kuder-Richardson 20 (KR-20). KR-20 value was 0.7 .

Finally, a 31-item questionnaire was prepared by an online survey maker. The questionnaire was sent to all the dental students in Iran who were enrolled in any clinical course. The questionnaire consisted of two sections, including the demographic part and a section associated with the knowledge and attitude. The demographic data included the following four items: age; gender; educational institution; and the semester. The second part of the questionnaire consisted of 27 items (Table 1). This section included nine true/false questions and eighteen multi-choice questions: 17 on prevention; four on the routes of transmission; three on risk assessment; and three on diagnosis, signs, and symptoms of COVID-19. There were 16 questions on knowledge and 11 questions on attitude. Partially-filled questionnaires were excluded from the study. Students who did not want to be part of the survey were not included.

A right answer was assigned 1 point and an incorrect/unknown answer was assigned 0 points. The total knowledge score ranged from 0 to 16 while the total attitude score ranged from 0 to 11 . The level of knowledge and attitude was reported as a percentage (sum of scores divided by the number of questions) and the higher the score, the better the knowledge or attitude of the student. Bloom's cut-off point was used to categorize the overall knowledge and attitude scores..$^{10}$ The level of knowledge was considered good if it was higher than $80 \%$ (13-16 points). If score was between $50 \%$ and $79 \%$ (8-12 points), the knowledge was considered moderate, and if it was lower than $50 \%$ (below 8 points) the knowledge was considered poor. The attitude was considered positive if the score was higher than $80 \%$ (more than 9 points), 


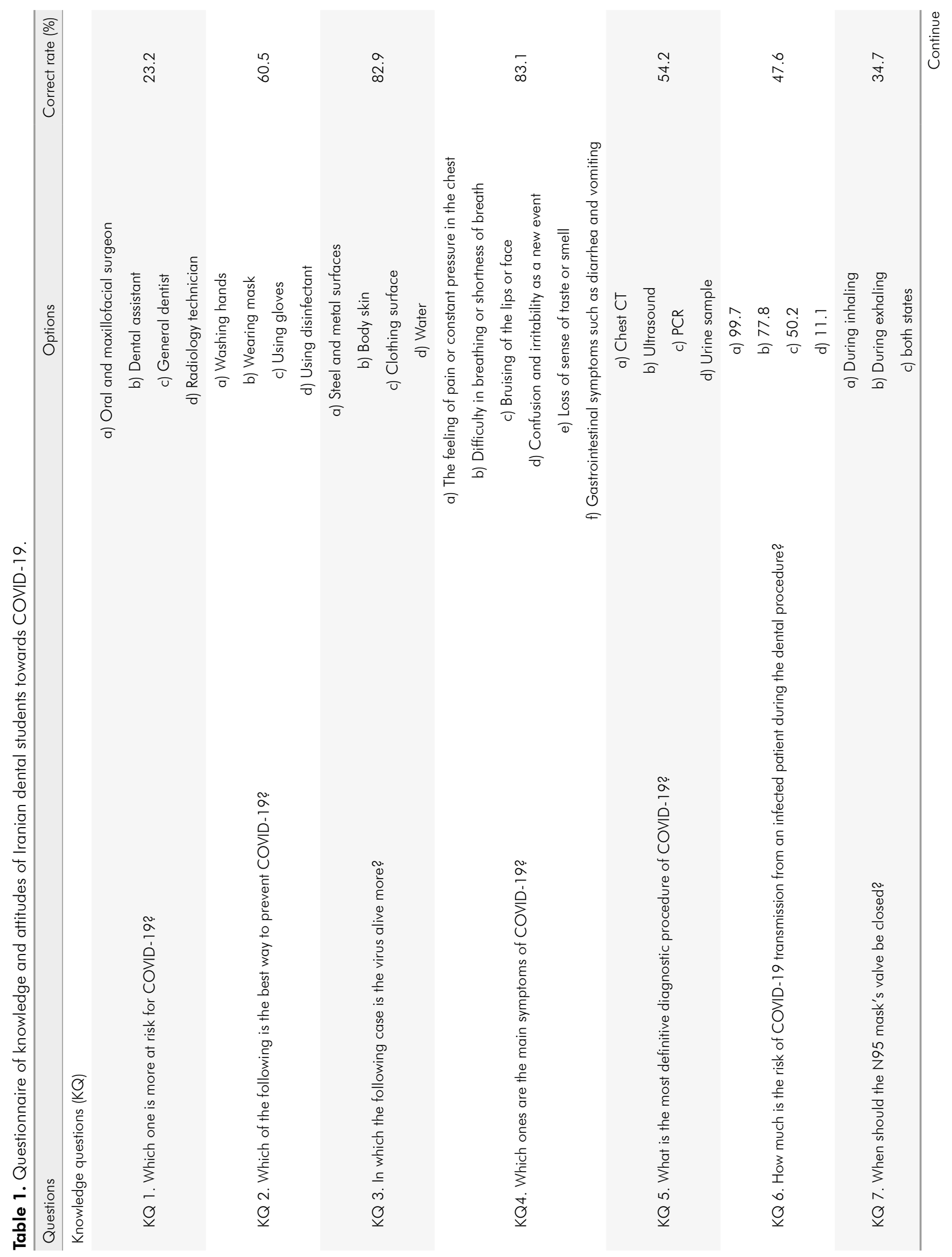


Knowledge and attitudes of Iranian dental students regarding infection control during the COVID-19 pandemic

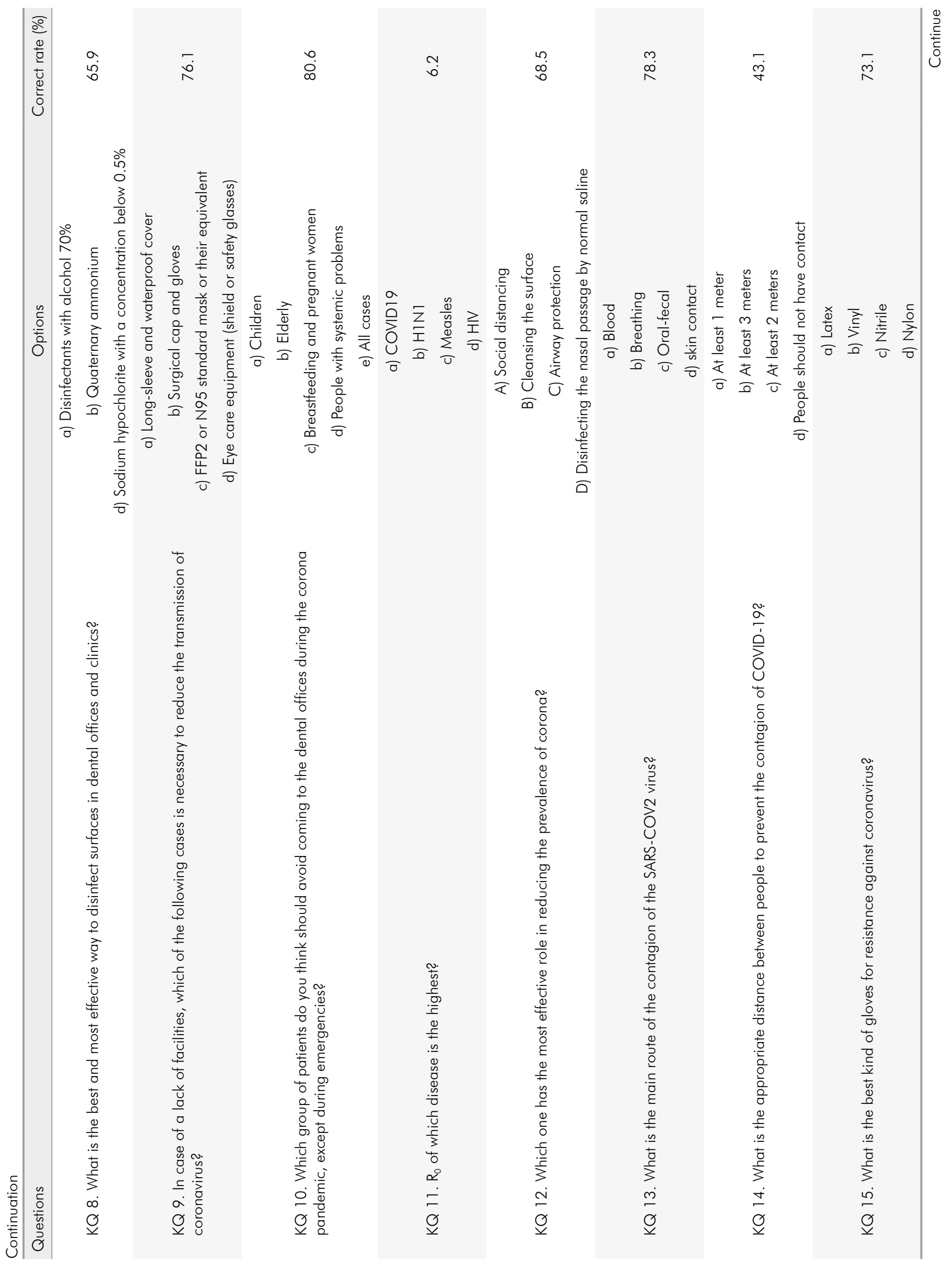




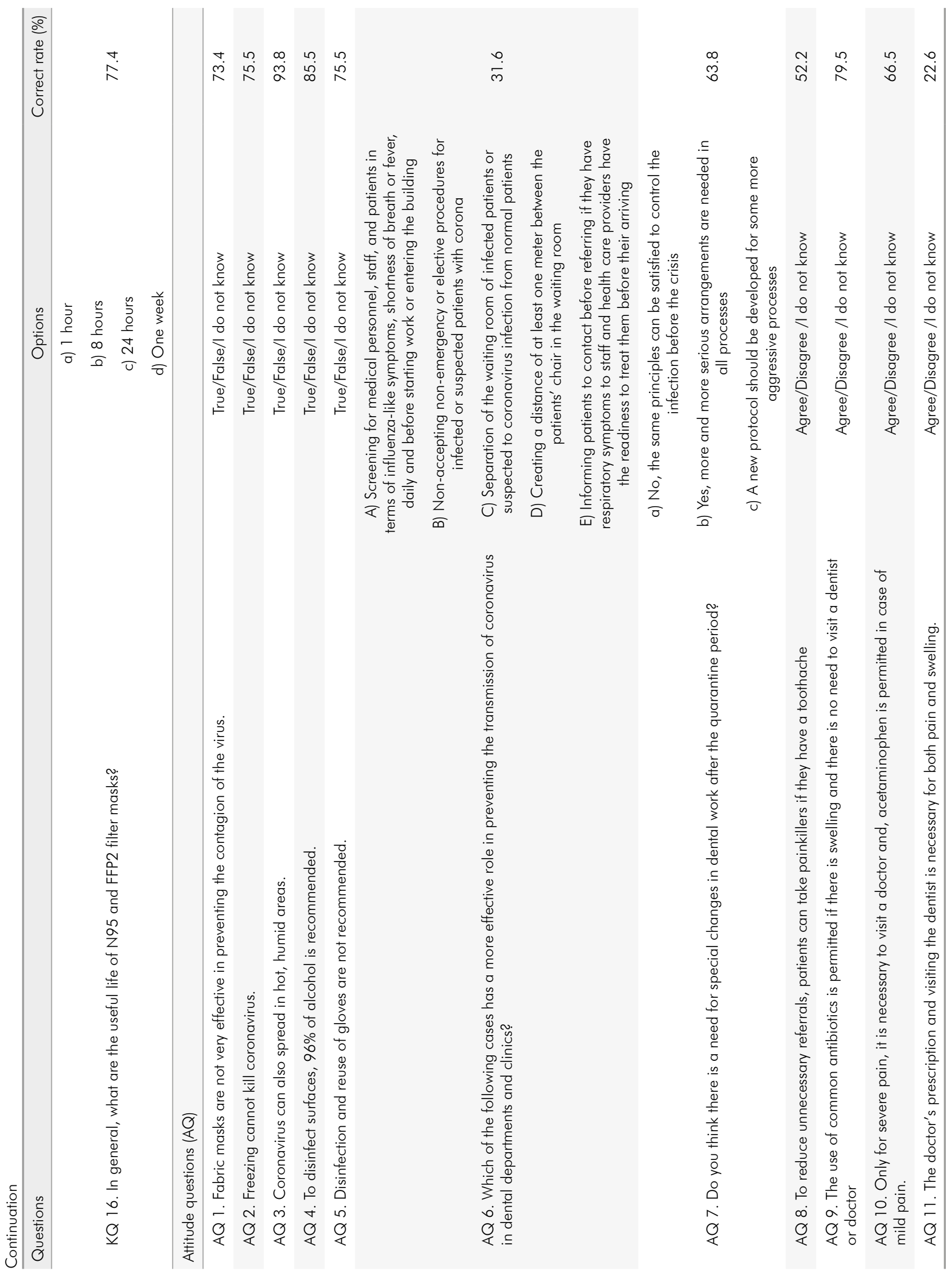


neutral if the score was between $60 \%$ and $79 \%$ (7 and 8 points), and negative if the score was lower than $59 \%$ (below 7 points).

\section{Ethical considerations}

Participants were informed of the purpose and design of the investigation and all the forms filled were de-identified. The procedures followed were according to the ethical standards of the responsible committee of the Semnan University of Medical Sciences.

\section{Statistical analysis}

The sample size was calculated by Cochran's sample size formula. The total number of students enrolled in clinical courses was about 10000 . The sample size was estimated at 370 by considering a margin of error of $0.05(\mathrm{~d}=0.05)$ and $95 \%$ confidence level $(z=1.96)$. Simple random sample allocation was performed to achieve the calculated sample size.

All data calculations were processed using the Statistical Package for Social Sciences statistical software (version 22; SPSS Inc.). Continuous variables are presented as means \pm SD for normally distributed data and as median (interquartile range) for non-normally distributed data; while categorical variables are presented as counts and percentages (\%) These data are also presented in tables and graphs. The two-sample $t$-test was used to compare the knowledge and attitude scores between the two genders. The correlation between the knowledge and attitude scores with the age and grade of the students was evaluated using Spearman's rho correlation coefficient (r). Multiple linear regression models were used to evaluate the adjusted relationship between the age, gender, and grade of students with their knowledge and attitude scores. Values of $P$ less than 0.05 were considered statistically significant.

\section{Results}

Five hundred and thirty-one students filled the questionnaires (211 male and 320 females). The mean age of the participants was $23.13 \pm 2.29$. The students were from 32 different universities. They were all enrolled in clinical courses (between the fifth and twelfth terms in Iran). The demographic data are presented in Table 2.

The mean knowledge score was $9.55 \pm 1.94$ (59.7\%). The mean attitude score was $7.26 \pm 1.79$ (66\%). There were no relationships between the demographic data and the level of the knowledge (Table 3). The level of knowledge of the students in three questions was significantly poor. In total, the answers of three questions were good, eight questions moderate, and five questions poor.

However, the attitude of the students was significantly associated with the grade and age of the participants $(\mathrm{r}=0.183, \mathrm{p}<0.001$ and $\mathrm{r}=0.150$, $p=0.001$, respectively) (Table 4). After adjusting for

Table 2. Demographic characteristics of participants.

\begin{tabular}{lccc}
\hline Characteristics & Number of participants (\%) & Knowledge score (mean \pm SD) & Attitude score (mean \pm SD) \\
\hline Gender & & & $0.66 \pm 0.34$ \\
Male & $211(39.7)$ & $0.6 \pm 0.35$ & $0.66 \pm 0.36$ \\
Female & $320(60.3)$ & $0.6 \pm 0.36$ & $0.62 \pm 0.33$ \\
Semester & & & $0.64 \pm 0.27$ \\
5 & $23(4.3)$ & $0.56 \pm 0.33$ & $0.65 \pm 0.36$ \\
6 & $129(24.3)$ & $0.6 \pm 0.36$ & $0.64 \pm 0.34$ \\
7 & $20(3.8)$ & $0.65 \pm 0.37$ & $0.72 \pm 0.36$ \\
8 & $106(20)$ & $0.59 \pm 0.37$ & $0.69 \pm 0.38$ \\
9 & $24(4.5)$ & $0.58 \pm 0.33$ & $0.68 \pm 0.2$ \\
10 & $130(24.5)$ & $0.6 \pm 0.35$ & $0.7 \pm 0.4$ \\
11 & $13(2.4)$ & $0.57 \pm 0.25$ & $0.6 \pm 0.37$ \\
12 & $86(16.2)$ & & \\
\hline
\end{tabular}

SD: standard deviation. 
Table 3. Results of regression analysis on factors associated with COVID-19 knowledge.

\begin{tabular}{lcccc}
\hline Variables & Coefficient & Standard error & $\dagger$ & $p$-value \\
\hline Gender & -.012 & 0.011 & -0.263 & 0.792 \\
Age & -.060 & 0.003 & -1.252 & 0.211 \\
Grade of education & .051 & 0.003 & 1.071 & 0.285 \\
University of education & -.027 & 0.001 & -0.622 & 0.534 \\
\hline
\end{tabular}

age and gender, the attitude of the students was only associated with the level of education $(p=0.001)$ (Table 4). The senior students showed a better attitude than juniors. The students in the eleventh grade portrayed the best attitude whilst the worst attitude towards COVID-19 in dentistry was portrayed by students in the sixth grade (Figure 1).

As for the educational institution, the students of Gorgan University displayed the highest level of knowledge (65.6\%) while the lowest level of knowledge was displayed by students of the University of Shahed (45.8\%) (Figure 2). The best attitude was portrayed by students of the University of Rafsanjan (81.8\%). Students of the universities of Qom portrayed the worst attitude (45.4\%) towards COVID-19 infection control in the field of dentistry.

\section{Discussion}

This is the first survey examining the knowledge of dental students in Iran regarding the COVID-19 pandemic. COVID-19 has spread all over the world, and now the WHO has declared this disease a global pandemic. ${ }^{2}$ The high transmission potential

Table 4. Results of regression analysis on factors associated with COVID-19 Attitude.

\begin{tabular}{lcccc}
\hline Variables & Coefficient & Standard error & $t$ & $p$-value \\
\hline Gender & -.011 & 0.014 & -0.244 & 0.808 \\
Age & .053 & 0.003 & 1.132 & 0.258 \\
Grade of education & 0.154 & 0.003 & 3.276 & 0.001 \\
University of education & -.037 & 0.001 & -0.863 & 0.389 \\
\hline
\end{tabular}

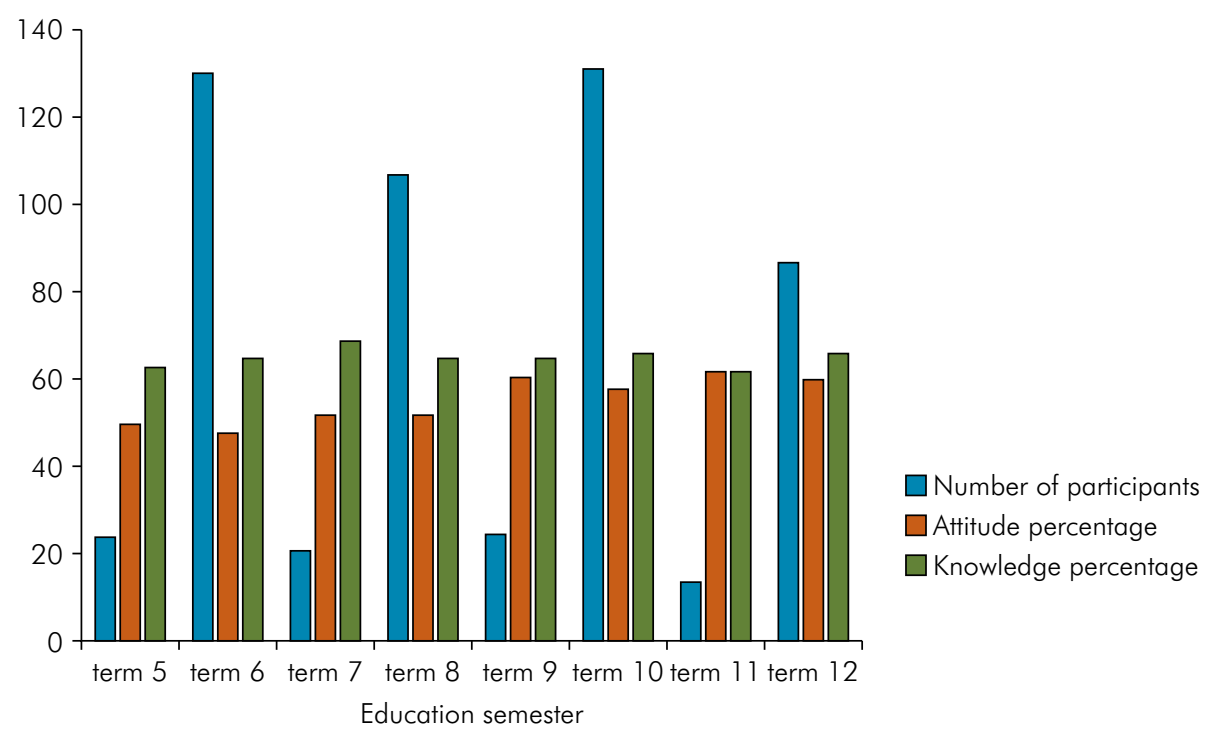

Figure 1. The distribution of students' cooperation, level of knowledge, and attitude according to the level of education. 


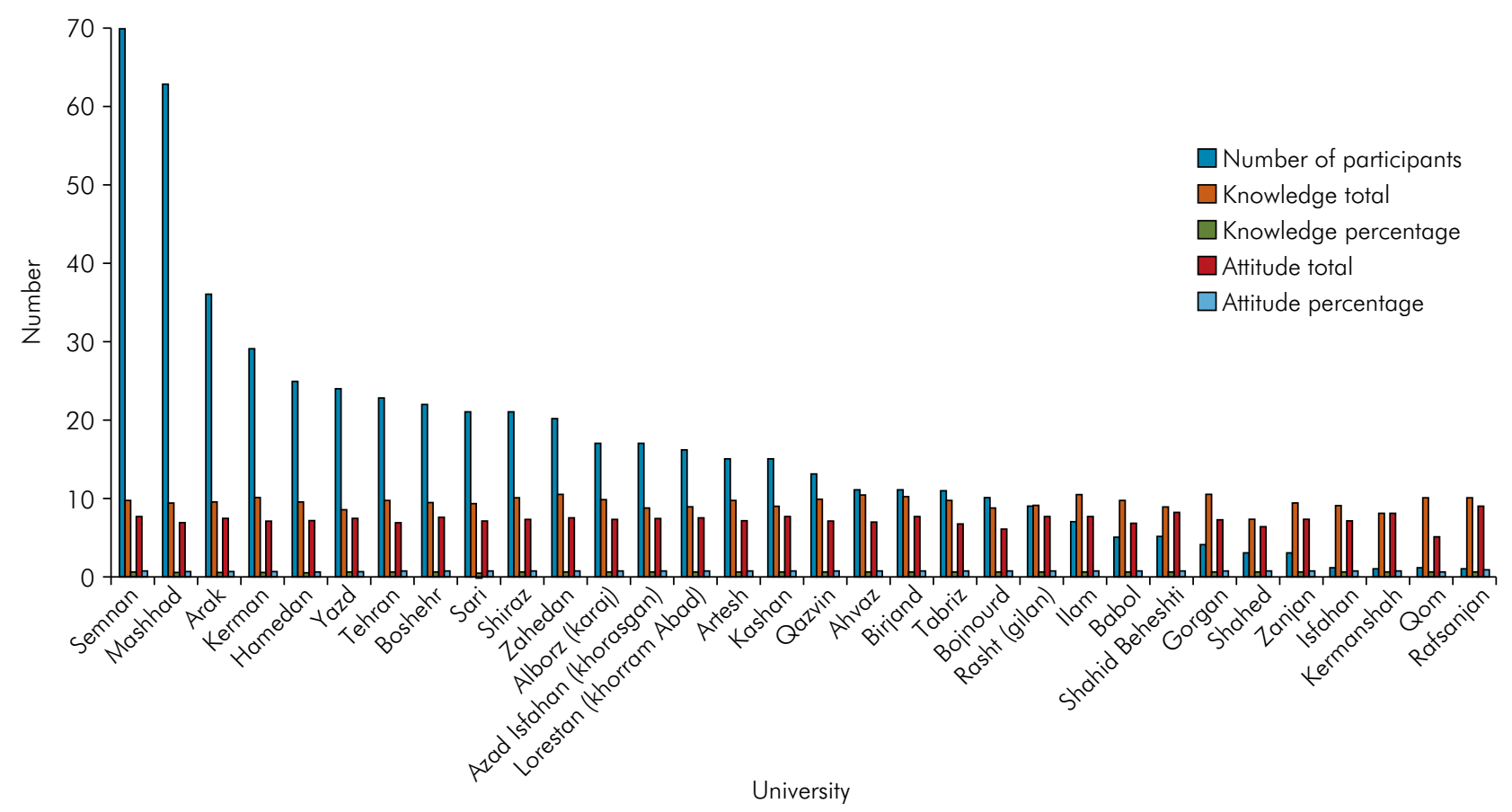

Figure 2. The distribution of students' cooperation, level of knowledge, and attitude according to the educational institution (university).

in lots of countries, especially Iran, has made the spread of this disease an emergency. ${ }^{11}$ Putting dental students at a high risk of getting infected, since this study aimed to evaluate the knowledge and attitudes of the Iranian dental students towards prevention, transmission routes, and the risk of infection of SARS-CoV-2, is aerosol and droplets being indicated in investigations as the most important routes of transmission of COVID-19. ${ }^{12}$ It was attempted to evaluate the knowledge and attitude of dental students enrolled in clinical courses about this topic because this population is directly involved in the treatment of the patients, which could lead to an exaggerated transmission of the novel coronavirus.

With several protocols for dentists during the COVID-19 outbreak having been reported in the literature ${ }_{1}^{14}$ patient management in the field of dentistry has been changed all around the world due to the outbreak of COVID-19.13 Infection control and patient management during the COVID-19 pandemic are much more vital in dental schools due the lack of experience among dental students. Furthermore, some dentists do not follow the protocols, which could lead to an uncontrollable spread of COVID-19.15
The questionnaire was delivered to the participants through social media tools such as Telegram, WhatsApp, and Instagram direct and they were in contact with the examiners to help fill the form. The survey maker website restricted the participants to answering each question only once by a putting a timer to reduce the possibility of participants browsing the Internet in search of correct answers. This could help reduce the study bias.

With similar studies having investigated the knowledge and attitude of dental and medical students towards influenza H1N1, ${ }^{16,17}$ the knowledge and attitude of medical and dental students about infectious diseases are important since they have an important role in preventing the spread of diseases, especially viral infections, to the community. Poor behavioral response of dental students to infectious diseases might place themselves and their patients at high risk and result in functional impairment of the health care system. ${ }^{18}$

A similar study evaluated the knowledge and attitudes of psychiatric hospital staff regarding COVID-19.19 They revealed that there is still a need for training programs on COVID-19 to improve the knowledge of medical staff. ${ }^{19}$ Increasing the knowledge 
of the population generally about COVID-19 is also important in the prevention of disease transmission. ${ }^{20,21}$

Five hundred and thirty-one students from 32 different universities were included in this study. The ages of the participants ranged from 20 to 38 years, with a mean of 23.12. More students of Semnan and Mashhad universities participated in the study than students of other faculties. The level of education ranged from the fifth to the twelfth grade, and all students were enrolled in clinical courses. A majority of the included students were in the sixth and tenth grades. The mean knowledge percentage was $59.7 \%$. Although the level of knowledge was not significantly associated with the level of education, the senior students demonstrated a higher level of knowledge than the juniors. The students provided significantly more incorrect responses to some questions. With a lack of knowledge being directly associated with the absence of training courses in dental faculties, and as an example, they did not know the $\mathrm{R}_{0}$ of different infectious diseases. They thought SARS-CoV-2 could spread in the population faster than other viral infections. In another case, they were not aware of the estimated risk of COVID-19 transmission in people that work in a dental clinic. Lots of dental schools in Iran have not prepared their students to confront COVID-19, whereas sooner or later, these faculties will be re-opened and place the students, professors, clinic staff, and patients at a very high risk of infection.

The mean attitude percentage was $66 \%$ and it was significantly associated with the level of education. The senior students were informed of the protocols and infection control strategies. The poor attitude of junior students put them and other hospital staff in danger.

The students of the Gorgan University portrayed the best attitude towards COVID-19 in the field of dentistry; however, their level of their knowledge was one of the lowest among the universities. These findings indicated that even though the students might not properly know about the various aspects of COVID-19 in general, they are aware of the proper behavior in their specific fields to reduce the transmission. This fact requires some well-scheduled training courses on COVID-19 aspects in the field of dentistry. Similar findings were observed in the universities of Babol and Qom. The students of these universities mentioned watching some infection control videos on webinars and Instagram.

The novel coronavirus and COVID-19 are new topics in medicine and, while there are some studies that investigate the knowledge of dentists about COVID-19, there is paucity of related researches evaluating the knowledge of dental students in the literature. Duruk et al. evaluated the attitude and behaviors of Turkish dentists towards the COVID-19 pandemic. Although the dentists were aware of the risks of the novel coronavirus transmission, they did not use protections such as N95 masks during dental practice. ${ }^{15}$ The authors revealed that the Turkish dentists were concerned with the risk of transmitting COVID-19 although their attitudes were inadequate. This study showed similar attitude level among dental students. These findings were a consequence of the inadequacy of training courses for dental students and full-fledged dentists.

Some studies have evaluated the knowledge and attitude of medical students towards COVID-19. ${ }^{22,23}$ Taghrir et al. ${ }^{23}$ evaluated the knowledge and attitude of Iranian medical students towards COVID-19. They showed high level of knowledge and preventive behaviors among medical students $(86.96 \%$ and $94.47 \%$, respectively). ${ }^{23}$ The higher knowledge level of medical students compared to the dental students (current study) could be associated with the courses they take in hospitals. No such courses are held for dental students. This lack of training courses might lead to the low level of knowledge and attitude of dental students toward infection control during pandemics like COVID-19.

In a study by Alzoubi et al. suggesting that social media and news were responsible for improving the knowledge and attitude of university students towards the COVID-19 pandemic, ${ }^{22}$ they investigated the knowledge and attitude of medical and non-medical students in Jordan regarding COVID-19. The knowledge score in their study was $81 \%{ }^{22}$ The findings of their study indicated higher knowledge and attitude levels than dental students (present study).

The overall score of knowledge and attitude seemed to be very low in the present study. The findings of the study indicated that the knowledge of Iranian dental students was poor in some cases. 
They did not know how to prevent transmitting the SARS-CoV-2 in dental clinics. Their lack of an appropriate attitude towards the COVID-19 in the field of dentistry makes the educational programmers worry about the re-opening of dental schools. The risk of transmitting the virus from infected patients to the healthcare staff and university professors is predicted to be high unless the students are prepared to battle this new life-threatening disease.

The findings of this study revealed that holding training courses and webinars on COVID-19 is an absolute necessity before asking dental students to perform procedures on patients. The poor and moderate levels of knowledge about infection control indicated that proven guidelines for dental practice should be presented to the dental students. Simulation courses on patients by the trainers should be held to show the students correct and appropriate behaviors in dental practice during the COVID-19 pandemic.

\section{Conclusion}

This study indicated the inadequate level of knowledge of the dental students of COVID-19 to protect themselves and the patients referred to the clinics. There is a need for training sessions and additional educational programs to improve the knowledge of dental students regarding the prevention strategies for COVID-19. Otherwise, the rate of infection would rise again when the dental schools are opened to offer their services. Further studies are required to assess the knowledge and practice of the students after holding training courses.

\section{Acknowledgment}

The authors would like to thank all the participants involved in the study and also the colleagues of all the universities included in the study for their cooperation and support.

\section{References}

1. Wang L, Wang Y, Ye D, Liu Q. Review of the 2019 novel coronavirus (SARS-CoV-2) based on current evidence. Int J Antimicrob Agents. 2020 Jun;55(6):105948. https://doi.org/10.1016/j.ijantimicag.2020.105948.; Epub ahead of print.

2. Cucinotta D, Vanelli M. WHO Declares COVID-19 a Pandemic. Acta Biomed. 2020;91(1):157-60. https://doi.org/10.23750/abm.v91i1.9397.

3. Sohrabi C, Alsafi Z, O'Neill N, Khan M, Kerwan A, Al-Jabir A, et al. World Health Organization declares global emergency: a review of the 2019 novel coronavirus (COVID-19). Int J Surg. 2020;76:71-6. https://doi.org/10.1016/j.ijsu.2020.02.034.

4. World Health Organization - WHO. Coronavirus disease 2019 (COVID-19): situation report, 182. Geneva: World Health Organization; 2020.

5. Baud D, Qi X, Nielsen-Saines K, Musso D, Pomar L, Favre G. Real estimates of mortality following COVID-19 infection. Lancet Infect Dis. 2020 Jul;20(7):773. https://doi.org/10.1016/S1473-3099(20)30195-X

6. Liu Y, Gayle AA, Wilder-Smith A, Rocklöv J. The reproductive number of COVID-19 is higher compared to SARS coronavirus. J Travel Med. 2020;27(2):1-4. https://doi.org/10.1093/iłm/taaa021

7. Nacoti M, Ciocca A, Giupponi A, Brambillasca P, Lussana F, Pisano M et al. At the epicenter of the Covid-19 pandemic and humanitarian crises in Italy: changing perspectives on preparation and mitigation. NEJM Catalyst. 2020 Mar. 21 [cited 2020 July 20]. Available from: https://catalyst.nejm.org/doi/full/10.1056/CAT.20.0080

8. Spagnuolo G, De Vito D, Rengo S, Tatullo M. COVID-19 outbreak: An overview on dentistry. Int J Environ Res Public Health. 2020 Mar;17(6):2094-2097. https://doi.org/10.3390/ijerph17062094.

9. Dave M, Seoudi N, Coulthard P. Urgent dental care for patients during the COVID-19 pandemic. Lancet. 2020;395(10232):1257. https://doi.org/10.1016/S0140-6736(20)30806-0

10. Seid MA, Hussen MS. Knowledge and attitude towards antimicrobial resistance among final year undergraduate paramedical students at University of Gondar, Ethiopia. BMC Infect Dis. 2018;18(1):312. https://doi.org/10.1186/s12879-018-3199-1

11. Shim E, Tariq A, Choi W, Lee Y, Chowell G (2020) Transmission potential and severity of COVID-19 in South Korea. Int J Infect Dis. 2020 Apr;93:339-344.https://doi.org/10.1016/j.ijid.2020.03.031

12. Guo H, Zhou Y, Liu X, Tan J. The impact of the COVID-19 epidemic on the utilization of emergency dental services. J Dent Sci. Forthcoming 2020. https://doi.org/10.1016/i.jds.2020.02.002

13. Rupf S, Hannig M. Changes of the patient management in dentistry during the pandemic caused by the SARS-Coronavirus 2: initial perspectives of a clinic of operative dentistry in Europe. Clin Oral Investig. 2020;24(7):2537-9. https://doi.org/10.1007/s00784-020-03351-z 
14. Cirillo N. COVID-19 outbreak: succinct advice for dentists and oral healthcare professionals. Clin Oral Investig. 2020;24(7):2529-35. https://doi.org/10.1007/s00784-020-03323-3

15. Duruk G, Gumu BO A Z. eyma, Çolak C. Investigation of Turkish dentists clinical attitudes and behaviors towards the COVID-19 pandemic: a survey study. Braz Oral Res. 2020;34:054.. https://doi.org/10.1590/1807-3107bor-2020.vol34.0054

16. Askarian M, Danaei M, Vakili V. Knowledge, attitudes, and practices regarding pandemic H1N1 Influenza among medical and dental residents and fellowships in Shiraz, Iran. Int J Prev Med. 2013;4(4):396-403.

17. Hasan F, Khan MO, Ali M. Swine Flu: Knowledge, attitude, and practices survey of medical and dental students of Karachi. Cureus. 2018;10:e2048. https://doi.org/10.7759/cureus.2048

18. Singh K, Bhat N, Chaudhary H, Asawa K, Sharda A, Agrawal A. Knowledge, attitude, behavioural response and use of preventive measures regarding pandemic HINI influenza outbreak among dental students in Udaipur city, India. Oral Health Prev Dent. 2012;10(4):339.

19. Shi Y, Wang J, Yang Y, Wang Z, Wang G, Hashimoto K, et al. Knowledge and attitudes of medical staff in Chinese psychiatric hospitals regarding COVID-19. Brain Behav Immun Health. 2020;4:100064. https://doi.org/10.1016/i.bbih.2020.100064

20. Zhong BL, Luo W, Li HM, Zhang QQ, Liu XG, Li WT, et al. Knowledge, attitudes, and practices towards COVID-19 among Chinese residents during the rapid rise period of the COVID-19 outbreak: a quick online cross-sectional survey. Int J Biol Sci. 2020;16(10):1745-52. https://doi.org/10.7150/ijbs.45221

21. Abdelhafiz AS, Mohammed Z, Ibrahim ME, Ziady HH, Alorabi M, Ayyad M, et al. Knowledge, perceptions, and attitude of egyptians towards the novel Coronavirus disease (COVID-19). J Community Health. 2020;45(5):1-10. https://doi.org/10.1007/s10900-020-00827-7

22. Alzoubi H, Alnawaiseh N, Al-Mnayyis A, Lubad M, Aqel A, Al-Shagahin H. COVID-19-knowledge, attitude and practice among medical and non-medical University Students in Jordan. J Pure Appl Microbiol. 2020;14(1):17-24. https://doi.org/10.22207/JPAM.14.1.04

23. Taghrir MH, Borazjani R, Shiraly R. COVID-19 and Iranian medical students: a survey on their related-knowledge, preventive behaviors and risk perception. Arch Iran Med. 2020;23(4):249-54. https://doi.org/10.34172/aim.2020.06 